\title{
Major trismus associated with succinylcholine administration in carbamate insecticide poisoning
}

\author{
Islem Ouanes, MD · Lamia Ouanes-Besbes, MD • \\ Fekri Abroug, MD
}

Received: 16 April 2009/ Accepted: 8 May 2009/Published online: 22 May 2009

(c) Canadian Anesthesiologists' Society 2009

\section{To the Editor,}

Succinylcholine, a hypnotic and depolarizing neuromuscular blocking agent, is a drug recommended for rapid sequence intubation. ${ }^{1}$ Organophosphates and carbamate insecticides, which may be used in suicide attempts, inhibit both plasma cholinesterase and acetylcholinesterase, and they may also extend the duration of action of succinylcholine and prolong neuromuscular blockade. ${ }^{2}$ We report a case of life-threatening trismus involving the delayed interaction between succinylcholine and carbamate poisoning.

An 18-year-old woman was admitted to the intensive care unit following a suicide attempt with a carbamate insecticide (methomyl). She had the following symptoms of severe carbamate poisoning: coma, fasciculations, salivation, lacrimation, myosis, bronchorrhea, and difficult breathing. Her arterial blood pressure was normal and her heart rate was 56 beats $\cdot \mathrm{min}^{-1}$. Tracheal intubation was performed after propofol administration, and mechanical ventilation was instituted. Plasma cholinesterase activity was low, $430 \mathrm{U} \cdot \mathrm{L}^{-1}$ (normal: 4000-6000 $\mathrm{U} \cdot \mathrm{L}^{-1}$ ). Activated charcoal was given and intravenous atropine was administered.

After 3 days, the patient experienced spontaneous gastric perforation and peritonitis for which surgical peritoneal irrigation was performed and intravenous antibiotics (amoxicillin-clavulanate and gentamicin) were administered. Her trachea was extubated by day 10 when both carbamate poisoning and peritonitis had clinically resolved. Her respiratory and hemodynamic status was stable, her body temperature was normal, and she was alert. Blood

I. Ouanes, MD · L. Ouanes-Besbes, MD · F. Abroug, MD ( $\square)$ CHU F. Bourguiba, Monastir, Tunisia

e-mail: f.abroug@rns.tn tests showed a white blood cell count of $7200 \mathrm{~mm}^{-3}$, hemoglobin $120 \mathrm{~g} \cdot \mathrm{L}^{-1}$, potassium $3.9 \mathrm{mmol} \cdot \mathrm{L}^{-1}$, and plasma cholinesterase activity $1500 \mathrm{U} \cdot \mathrm{L}^{-1}$. Less than $30 \mathrm{~min}$ after tracheal extubation, the patient's respiratory status worsened because of major bronchorrhea and inefficient cough. Tracheal intubation was then attempted after the simultaneous administration of propofol $150 \mathrm{mg}$ and succinylcholine $60 \mathrm{mg}$ intravenously. Within seconds, a strong trismus, or spasm of the masseter muscles, was observed, preventing mouth opening and orotracheal intubation. Despite administration of oxygen via bag and a face mask, sustained oxygen desaturation occurred throughout the 20-min intubation procedure (lowest recorded value, 84\%). A fibroscopy-guided nasotracheal intubation was therefore attempted, during which cardiac arrest occurred prompting immediate cardiopulmonary resuscitation. Oxygen delivery continued via bag and face mask and epinephrine (total dose, $6 \mathrm{mg}$ ) was administered. Fibreoptic nasotracheal intubation was ultimately successful by the 20th minute, and return of spontaneous circulation was achieved by the 25th minute. Mechanical ventilation was instituted, and sedation was provided with midazolam and remifentanil. Trismus progressively subsided between 4 and $8 \mathrm{~h}$ following its onset. Despite recovery of normal blood pressure and oxygenation, the electroencephalogram performed one day following the hypoxic episode indicated a pattern compatible with brain death. The patient died 3 days later.

This report shows that administration of succinylcholine might be associated with severe trismus even late in the setting of carbamate poisoning; therefore, administering succinylcholine in this setting should be considered contraindicated. Using the Naranjo adverse drug reaction probability scale, ${ }^{3}$ we calculated a score of 6 (a score of 5-8 out of 13 indicates a probable relation between the 
event and the suspected drug). Indeed, major trismus rapidly followed succinylcholine administration, and neither the concurrent disease nor the simultaneous drugs could account for the trismus. Conversely, trismus can be explained by the association of succinylcholine and poisoning by acetylcholinesterase inhibitors. Succinylcholine is a depolarizing agent that binds to acetylcholine receptors at the neuromuscular junction producing desensitization of these receptors. ${ }^{4}$ Succinylcholine opens myocyte ion channels with exit of potassium ions and entry of sodium ions, an action that is similar to that of acetylcholine itself. Therefore, it induces a depolarization and generates a muscle action potential that is maintained until succinylcholine is hydrolyzed by plasma cholinesterase. Cholinesterase inhibition, due to carbamates or organophosphates, results in accumulation of acetylcholine and persistent activation of acetylcholine receptors at the neuromuscular junction and in the autonomic nervous systems. ${ }^{5}$ Cholinesterase inhibitors can therefore potentiate succinylcholine effects.

Conflicts of interest None declared.

\section{References}

1. Rasmussen LS, Viby-Mogensen J. Rapid sequence intubationhow? Acta Anaesthesiol Scand 2007; 51: 787-8.

2. Naguib M, Samarkandi AH, Abdullah K, Riad W, Alharby SW. Succinylcholine dosage and apnea-induced hemoglobin desaturation in patients. Anesthesiology 2005; 102: 35-40.

3. Naranjo CA, Busto U, Sellers EM, et al. A method for estimating the probability of adverse drug reactions. Clin Pharmacol Ther 1981; 30: 239-45.

4. Naguib M, Samarkandi A, Riad W, Alharby SW. Optimal dose of succinylcholine revisited. Anesthesiology 2003; 99: 1045-9.

5. Durant NN, Katz RL. Suxamethonium. Br J Anaesth 1982; 54: 195-208. 